\title{
Computertomografie voor de detectie van longnodulen bij de hond
}

\author{
${ }^{1}$ K. Kromhout, ${ }^{1}$ A. Wouters, ${ }^{1}$ I. Gielen \\ ${ }^{1}$ Vakgroep Medische Beeldvorming en Orthopedie van de Kleine Huisdieren \\ Faculteit Diergeneeskunde, Universiteit Gent, Salisburylaan 133, 9820 Merelbeke \\ kaatje.kromhout@UGent.be
}

\section{AMENVATTING}

Computertomografie is de laatste jaren meer en meer beschikbaar in de diergeneeskunde. Een belangrijke toepassing is de detectie van longnodulen bij kankerpatiënten. Het vroegtijdig opsporen is essentieel voor het bepalen van de therapie en de prognose van de ziekte. In dit artikel worden het gebruik, de meerwaarde en de beperkingen van deze beeldvormingstechniek beschreven.

\section{INLEIDING}

Kanker is een van de meest voorkomende doodsoorzaken bij honden en katten. Bij de diagnose, klinische stagering, therapieplanning en prognose van tumoren spelen beeldvormingstechnieken een belangrijke rol. Zo leveren computertomografie (CT) en magnetische resonantie (MR) accurate driedimensionale informatie over de lokalisatie van de massa. Deze informatie kan helpen bij eventuele stereotactisch CT-begeleide biopten, radioablatie en chirurgische resectie van het proces (LeCouteur, 1999). De aanwezigheid van verre metastasen is bepalend voor de prognose en de uiteindelijke therapie voor het dier. De manier van metastaseren verschilt naargelang de tumor. Zo breiden bepaalde neoplasieën, waaronder de meeste sarcomen en mammatumoren, uit via de lymfatische route (i.e. naar lokale en regionale lymfeknopen) en andere, zoals mastceltumoren, carcinomen en maligne melanomen, via de hematogene route (i.e. naar de longen en parenchymateuze organen).

Longmetastasen zorgen voor een minder gunstige prognose. Zo zijn volgens Watson (2002) bij de initiële diagnose van osteosarcoom bij $90 \%$ van de honden micrometastasen aanwezig en heeft 15\% klinisch detecteerbare metastasen. Na behandeling bedraagt de gemiddelde overlevingstijd vier maanden tot twee jaar. Het overlijden van de honden is meestal te wijten aan pulmonaire metastasen. Bij het eerste lichamelijk onderzoek van vrouwelijke honden met maligne mammatumoren heeft 25 tot 50\% longmetastasen (Hedlund, 2007). Het vroegtijdig opsporen is dus van essentieel belang.

De evaluatie van het longparenchym gebeurt in de dierenartsenpraktijk met behulp van radiografie van de thorax (Nemanic et al., 2006), een goedkope eerste screening van de longen, maar helaas met een aantal beperkingen (Müller, 1991). Nodulen kleiner dan $7 \mathrm{~mm}$ worden vaak niet gedetecteerd (Nemanic et al.,
2006). Verder kunnen bepaalde nodulen gemist worden door de superpositie van intra- of extrathoracale structuren over de longvelden (Johnson et al., 2004; Gielen en van Bree, 2003; Schuller et al., 2005; Henninger, 2003; Joly et al., 2009; Cipone et al., 2003; Mantis en Baines, 2007). Veterinaire studies hebben aangetoond dat CT een sensitievere techniek is dan radiografie, wat de detectie van longmetastasen betreft (Nemanic et al., 2006; Alexander et al., 2012; Armbrust et al., 2012). Er worden significant meer nodulen in longlobi gedetecteerd met behulp van CT dan met radiografisch onderzoek. De detectiedrempel ligt dus veel lager bij CT (LeBlanc en Daniel, 2007). Zelfs nodulen met een grootte van $1 \mathrm{~mm}$ kunnen aangetoond worden (Nemanic et al., 2006).

In dit artikel worden de mogelijkheden, beperkingen en het gebruik van CT voor de detectie van nodulen in de thorax van honden beschreven.

\section{HET GEBRUIK VAN CT BIJ DE BEELDVOR- MING VAN DE THORAX}

Bij een CT-onderzoek is algemene anesthesie noodzakelijk om bewegingsartefacten te voorkomen. Om een meer normale positie van het hart en andere mediastinale structuren te verkrijgen, wordt de hond in sternale decubitus gepositioneerd (Gielen en van Bree, 2003; Nemanic et al., 2006).

Omdat de patiënt tijdens het onderzoek in apneu wordt gebracht, kan het opsporen van nodulen optimaal gebeuren dankzij de betere en langer aanhoudende longinflatie. Dit resulteert voornamelijk in een betere detectie ter hoogte van de overgang tussen de met lucht gevulde longen en de weke delen, zoals de thoraxwand en het diafragma-oppervlakte. Een meer gevulde long zorgt ook voor een beter beeldcontrast tussen de nodulen en het longweefsel (Burk, 1991; Johnson et al., 2004; Nemanic et al., 2006). 
Standaard dient men tijdens het onderzoek een intraveneuze, joodhoudende contraststof toe. Het gebruik van contrastmedia verbetert het zachteweefselcontrast en helpt neoplastische letsels en hun uitbreiding in omgevende weefsels beter te definiëren. Het toegediende contrastmiddel accumuleert in sterk doorbloede weefsels en in weefsels met verhoogde vasculaire permeabiliteit (LeBlanc en Daniel, 2007). Verder is er een betere aflijning van de bloedvaten en een duidelijke differentiatie tussen normale en abnormale vasculaire structuren mogelijk (Otoni et al., 2010).

\section{MEERWAARDEN EN BEPERKINGEN VAN COMPUTERTOMOGRAFIE}

\section{Meerwaarden}

CT is sensitiever dan radiografie voor het detecteren van wekedelennodulen. Deze hogere sensitiviteit is te wijten aan de betere contrastresolutie (Nemanic et al., 2006; Schuller et al., 2005; Joly et al., 2009; Mantis en Baines, 2007; Vignoli et al., 2008; Gielen et al., 2003). CT toont een goed onderscheid tussen verschillende weefseldensiteiten (meer grijswaarden, meer contrast) (Johnson et al., 2004; Schuller et al., 2005; Burk, 1991; Henninger, 2003, De Rycke et al., 2005; Cipone et al., 2003). Ook kunnen kleine veranderingen in orgaangrootte, vorm, aflijning en positie aangetoond worden (De Rycke et al., 2005). CT onderscheidt pleuraal vocht van wekedelenstructuren, waardoor nodulen niet meer overschaduwd worden door pleurale effusie (Nemanic et al., 2006).

Met computertomografie kunnen reeds nodulen van $1 \mathrm{~mm}$ groot gedetecteerd worden; met conventionele radiografie is dat slechts vanaf $7 \mathrm{~mm}$. (Nemanic et al., 2006). Bovendien worden met CT een groter aantal longnodulen en nodulen met onscherp afgelijnde randen aangetoond (Figuur 1).

Door het maken van dwarsdoorsneden wordt de superpositie van intra- of extrathoracale structuren over de longvelden vermeden (Johnson et al., 2004; Gielen en van Bree, 2003; Schuller et al., 2005). Het voordeel daarvan is dat meerdere nodulen opgespoord worden in de middelste en caudale regio's, wat met radiografie niet het geval is (Alexander et al. 2012). Dit is belangrijk omdat de meeste primaire pulmonaire tumoren bij honden in de rechter caudale longlob voorkomen (Rissetto et al., 2008).

Aan de hand van transversale beelden kunnen reconstructies gemaakt worden in het sagittale en dorsale vlak (Schuller et al., 2005; Mantis en Baines, 2007) evenals multiplanaire reconstructies om verdachte letsels efficiënter te beoordelen (Johnson et al., 2004; Mantis en Baines, 2007; Gielen et al., 2003). Bij een multiplanaire reconstructie kan onderscheid gemaakt worden tussen atelectase en een tumoraal proces en tussen een ontsteking en een tumoraal proces (Henninger, 2003). Ook gezwellen in de thorax kunnen op die manier gedifferentieerd worden van vochtaccumulatie in het mediastinum of de pleura (Gielen en van Bree, 2003). Tevens zijn veranderingen in de pleura en aan de mediale zijde van de ribben te zien. Na intraveneuze contrasttoediening is longweefsel met pathologie duidelijk zichtbaar, omdat de viscerale en pariëtale pleura op dit niveau verdikt en onregelmatig zijn en duidelijk contrast opnemen (Burk,1991).

Onder CT-begeleiding kunnen zeer accuraat biopten genomen worden. Dit is noodzakelijk wanneer bijkomende informatie voor de diagnose, het stageren



Figuur 1. Verdeling van het aantal thoracale nodulen, afhankelijk van hun grootte gedetecteerd door CT alleen (wit) en door CT en thoraxradiografie (zwart) (naar Nemanic et al., 2006). Het schema toont duidelijk aan dat de meeste nodulen onder de $7 \mathrm{~mm}$ enkel met CT kunnen worden aangetoond. 
en de behandeling gewenst is. Het nemen van longbiopten is eenvoudig en gebeurt doorgaans met de losse hand (Gielen et al., 2003; Johnson et al., 2004; Vignoli et al., 2008).

\section{Beperkingen}

CT heeft een lagere specificiteit dan thoraxradiografie voor de detectie van pulmonaire metastatische nodulen. Dit komt voornamelijk omdat er met CT een groter aantal kleine, niet-neoplastische en dus klinisch niet-relevante pulmonaire nodulen - in de humane geneeskunde 'ditzels' genoemd (Munden en Hess, 2001) - gedetecteerd worden (Nemanic et al., 2006). CT van de longen kan dus leiden tot valspositieve resultaten met onnodige operaties tot gevolg (McCulloch et al., 2006).

Voor een CT-onderzoek moeten de dieren onder algemene anesthesie gebracht worden (Schuller et al., 2005; Rivero et al., 2005). De onderzoeken duren ook redelijk lang, waardoor de patiënt blootgesteld wordt aan hoge stralingsdosissen (Ohlerth en Scharf, 2007; Rivero et al., 2005).

Een andere beperking komt door de lokalisatie van de nodulen. Wanneer de nodulen zich in een zone met atelectase bevinden, is het mogelijk dat deze letsels niet gezien worden (Nemanic et al., 2006). Atelectase bevindt zich meestal ventraal in het longveld (Figuur 2). Pulmonaire compressie wordt aanzien als een rechtstreeks gevolg van de druk die het hart uitoefent (Ahlberg et al., 1985). Bovendien hebben de dunnere ventrale regio's een grotere relatieve oppervlakte per volumeratio en een grotere soepelheid, waardoor deze regio's vlugger collaberen dan andere longgebieden (Lord en Gomez, 1985). Door de hond sternaal te positioneren tijdens de CT en de tijd te beperken tussen de inductie van de anesthesie en het begin van het onderzoek kan het voorkomen van atelectase tot een minimum beperkt worden.

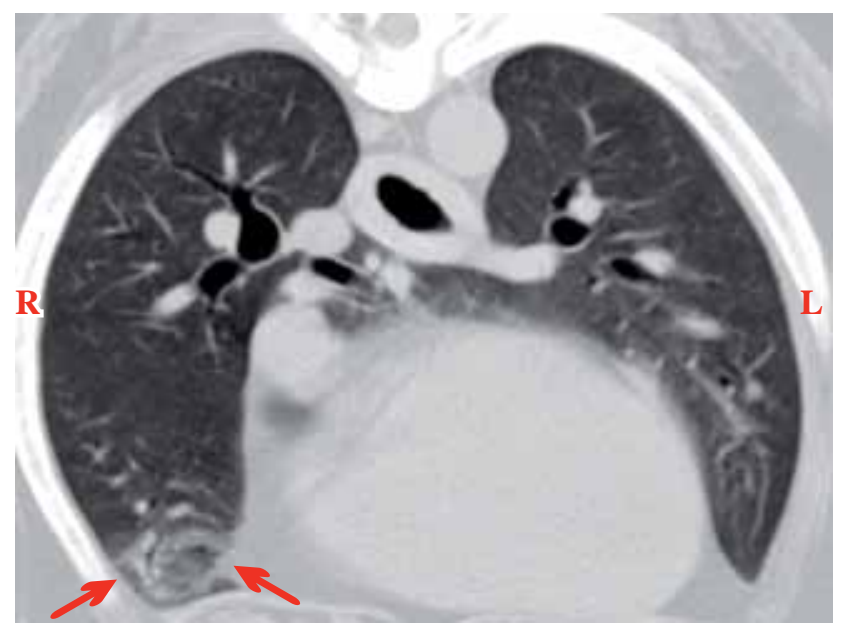

Figuur 2. Dwars CT-beeld door de thorax (longvenster). Ventraal ter hoogte van de rechterlongkwab is een zone van atelactase zichtbaar (rode pijlen).
Tot slot kunnen de ademhaling en het hart bewegingsartefacten veroorzaken (Gielen en van Bree, 2003; Henninger, 2003; Ohlerth en Scharf, 2007). Multislice CT-toestellen, een korte scantijd en artificiële respiratie kunnen deze artefacten beperken (Gielen en van Bree, 2003).

\section{NODULE OF NIET?}

Metastasen onderscheiden van benigne letsels op CT-beelden is op zich een uitdaging. Enkele karakteristieken kunnen een vermoeden van maligniteit bevestigen: de grootte, de afwezigheid van mineralisaties en de groei van de nodule. De groei van de nodule is het meest betrouwbare kenmerk (Midthun, 2007). Ook de typische morfologie en verdeelpatronen van de letsels zijn een indicatie (Schuller et al., 2005).

Op CT-beelden worden longmetastasen herkend als multipele, homogene, solide en duidelijk afgelijnde nodulen (Figuur 3). Ze komen meestal onregelmatig verspreid voor over het volledige longparenchym (Waters et al., 1998; Schuller et al., 2005), overwegend in de middelste of perifere delen. Ze zijn niet hol en verplaatsen of obstrueren de bronchi niet. De mineralisatie van metastatische nodulen is zeldzaam en de grootte van de nodulen varieert (Dennis et al, 2010). Nodulen van 1-3mm diameter of miliaire nodulen zijn diffuus verspreid met variërende densiteiten die grotere gehelen kunnen vormen (Figuur 4). Dit is meestal het gevolg van de hematogene of lymfatische verspreiding van pathogene of neoplastische cellen. De aanwezigheid van hilaire lymfadenopathie is hierbij mogelijk (Dennis et al., 2010), bijvoorbeeld bij metastatische thyroïd- of mammatumoren (carcinoom) of (eerder zelden) multipele myeloom. Grote nodulen (3-40mm) of metastatische tumoren zijn willekeurig verspreid en welomschreven. 'Cannonball' nodulen komen voornamelijk voor bij osteosarcomen. Er kunnen holtes aanwezig zijn die lucht bevatten (Figuur 5).

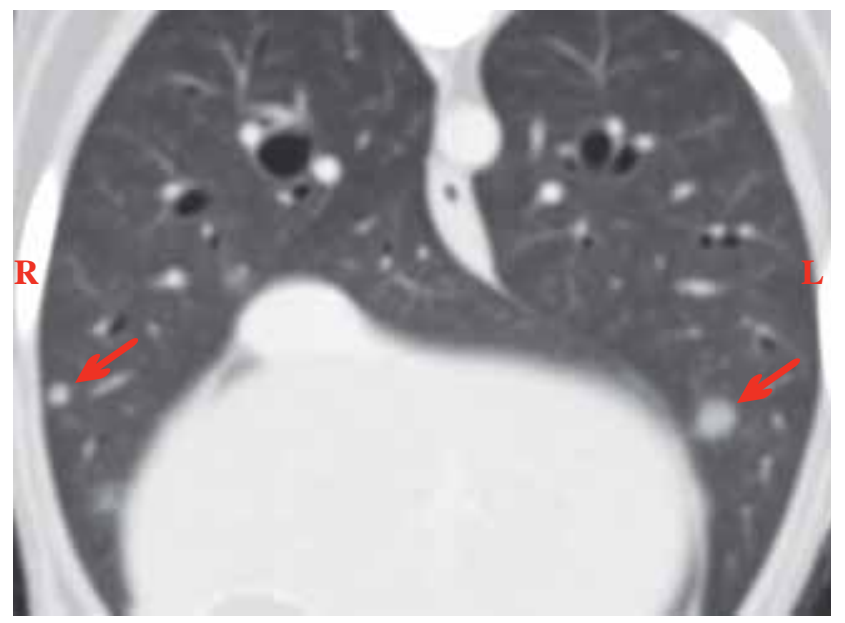

Figuur 3. Dwars CT-beeld door de thorax (longvenster). Bilateraal in de longen zijn er multipele kleine (2-4 mm), hyperdense, ronde, metastatische nodulen zichtbaar (rode pijlen). 


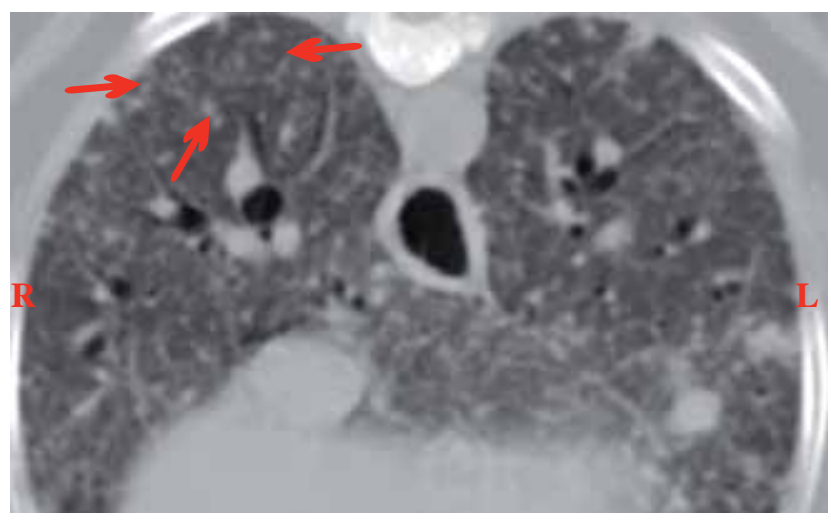

Figuur 4. Dwars CT-beeld door de thorax (longvenster). Ter hoogte van de rechterlongkwab zijn er diffuus verspreide miliaire nodulen zichtbaar (tussen de rode pijlen). Deze nodulen komen voornamelijk voor bij carcinomen.

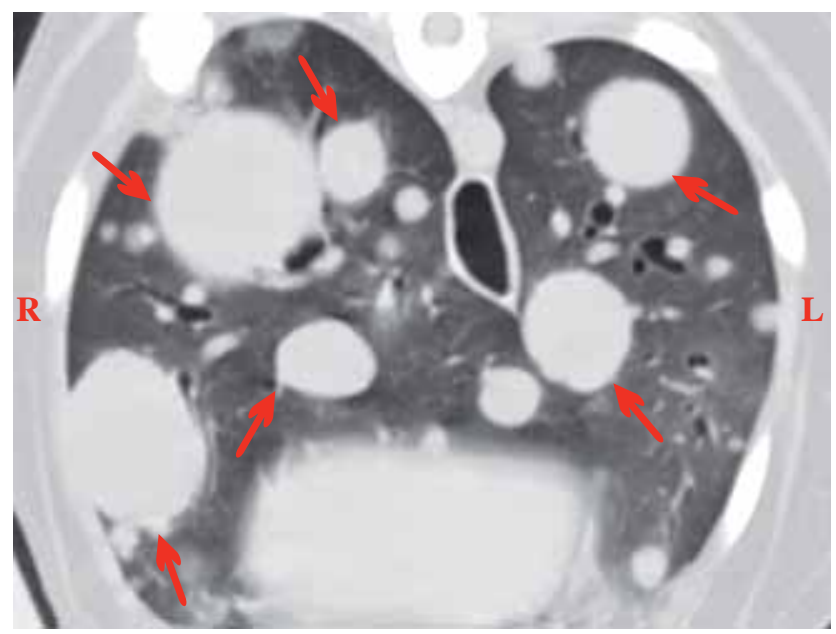

Figuur 5. Dwars CT-beeld door de thorax (longvenster). Bilateraal in de longen zijn er multipele, grote 'cannonball' nodulen (20-40 mm), metastasen zichtbaar (rode pijlen).

Contrasttoediening kan helpen bij het differentiëren van nodulen aangezien de vasculariteit verschilt. In de humane literatuur wordt gesteld dat de afwezigheid van sterke contrastcaptatie ( $<25$ 'houndsfield units') een indicatie is voor het goedaardige karakter van de nodule (Swensen et al., 2000).

Verschillende condities kunnen een valse impressie geven, zoals leeftijdsgebonden nodulen die incidenteel kunnen voorkomen op het CT-beeld. Subpleurale of pulmonaire osteomen zijn osseuze metaplasieën die zich juist onder de viscerale pleura aan het longoppervlakte in het interstitium bevinden; een vorm van heterotopische botvorming buiten het skelet (Figuur 6). Het zijn welomschreven gemineraliseerde focale nodulen (1-4 mm) met een predispositie voor de ventrale longvelden, maar ze kunnen over de volledige long voorkomen. Collies en shelties zijn gepredisponeerd voor deze veranderingen. Osteomen komen voornamelijk voor bij oudere honden en grote rassen (Berry, 2007). Pulmonaire bloedvaten - voornamelijk 'end-on' - kunnen verkeerdelijk aanzien worden als een nodule, voornamelijk in regio's waar bloedvaten verticaal georiënteerd zijn, ter hoogte van de apices (Davis, 1991) (Figuur 7). Daar een bloedvat in de nabijheid van een bronchus ligt, een staart heeft (de grootte neemt af naar de periferie toe), de densiteit hoger is door de grotere dikte en diepte van het bloedvat en omdat een bloedvat goed afgelijnd is, is geen twijfel mogelijk. De beste methode om nodulen van bloedvaten te onderscheiden, is vertakkingen opsporen en verdachte structuren op opeenvolgende sneden volgen (Davis, 1991). Indien er slechts één nodule aanwezig is, is het niet zeker of het al dan niet een metastase betreft. Een nodule wordt omschreven als een wekedelenmassa of een gemineraliseerde structuur die compressie uitoefent op het longweefsel of een deel van de luchthoudende portie van de longen vervangt. De differentiaaldiagnosen zijn onder andere een primaire longtumor, granuloom, abces, cyste, vochthoudende bulla, mucus bevattende bronchus en een hematoom. In gebieden waar er endemisch nodulaire schimmelaandoeningen, zoals histoplasmose, voorkomen, is een schimmeloorsprong van de nodule het meest aannemelijk. Metastasen zijn het meest waarschijnlijk als er een primaire tumor aanwezig is met een hoog metastatisch potentieel. Hoe chronischer de primaire tumor is, hoe groter de kans is dat de aanwezige nodulen metastasen zijn. Indien men niet zeker is van de uiteindelijke diagnose of de herkomst van de nodule, is een followup CT-scan na vier tot zes weken aan te raden.

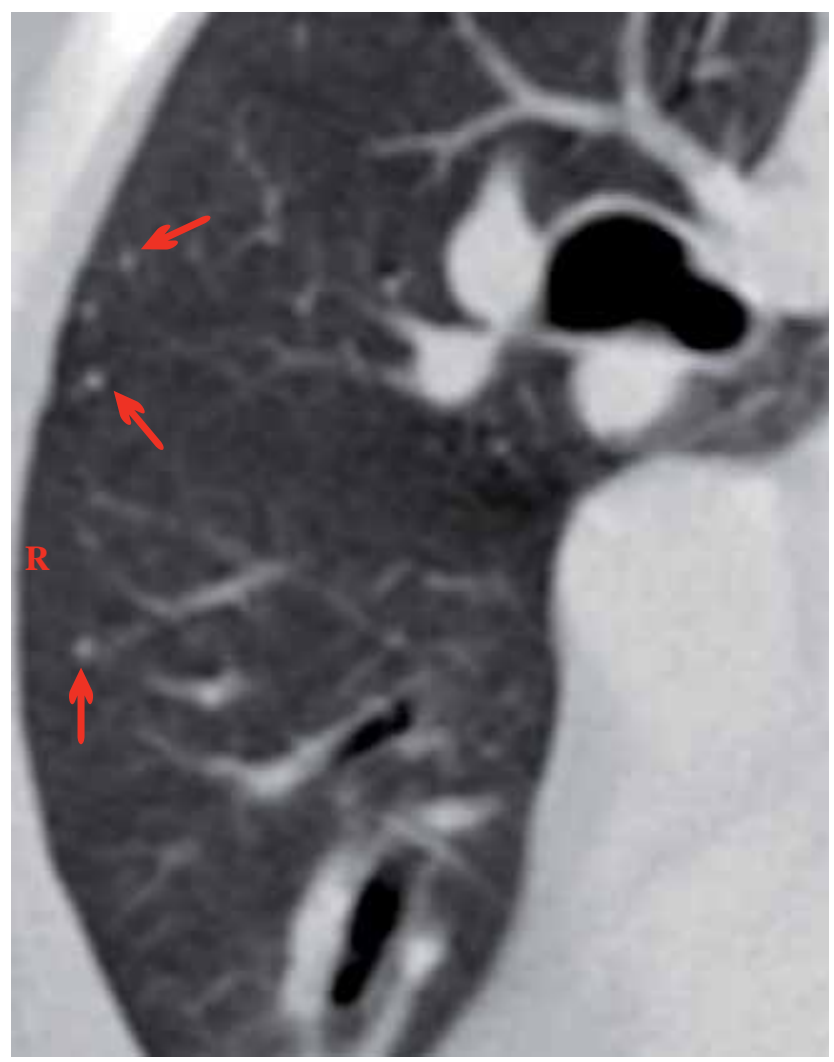

Figuur 6. Dwars CT-beeld door de thorax (longvenster). Ter hoogte van de rechterlongkwab zijn er meerdere kleine, ( $\pm 1 \mathrm{~mm})$ sterk hyperdense (gemineraliseerde) nodulen (osteomen) zichtbaar (rode pijlen). 




Figuur 7. Dwars CT-beeld door de thorax (longvenster) ter hoogte van een pulmonair bloedvat. A. Ter hoogte van de rechterlongkwab is er een kleine, hyperdense, ronde zone zichtbaar = 'end-on' bloedvat (rode pijl). $\mathrm{B}$. Er is een duidelijke staart aanwezig (groene pijl).

\section{CONCLUSIE}

$\mathrm{CT}$ is meer en meer beschikbaar in Belgische dierenklinieken. Aangezien CT accurater is dan thoraxradiografie voor het diagnosticeren van kleine pulmonaire nodulen, is deze techniek net zoals in de humane geneeskunde de techniek bij uitstek voor het screenen van kankerpatiënten. De hogere kostprijs, de noodzaak van anesthesie en de daaraan verbonden risico's blijven een nadeel van CT.

\section{LITERATUUR}

Ahlberg N.E., Hoppe F., Kelter U., Svensson L. (1985). A computed tomographic study of volume and X-ray attenuation of the lungs of beagles in various body positions. Veterinary Radiology \& Ultrasound 26, 43-47.

Alexander K., Joly H., Blond L., D’Anjou M.A., Nadeau M.E., Olive J., Beauchamp G. (2012). A comparison of computed tomography, computed radiography, and filmscreen radiography for the detection of canine pulmonary nodules. Veterinary Radiology \& Ultrasound 53, 258265.

Armbrust L.J., Biller D.S., Bamford A., Chun R., Garrett L., Sanderson M.W. (2012). Comparison of three-view thoracic radiography and computed tomography for detection of pulmonary nodules in dogs with neoplasia. Journal of American Veterinary Medical Association 240, 1088-1094.

Berry C.R., Graham J.P., Thrall D.E. (2007). Interpretation paradigms for the small animal thorax. In: Textbook of Veterinary Diagnostic Radiology. 5th Ed., Saunders, Philadelphia, 462-485.

Burk R.L. (1991). Computed tomography of thoracic diseases in dogs. Journal of the American Veterinary Medical Association 199, 617-621.

Cipone M., Diana A., Gandini G., Fava D., Trenti F. (2003). Use of computed tomography in thoracic diseases of small animals. Veterinary Research Communications 27, 381-384.

Davis S.D. (1991). CT evaluation for pulmonary metastases in patients with extrathoracic malignancy. Radiology 180, $1-12$.

Dennis R., Kirberger R.M., Barr F., Wrigley R.H. (2010). Lower respiratory tract. In: Handbook of Small Animal Radiology and Ultrasound. 2nd Ed., Elsevier ltd., Edinburgh, 145-173.

De Rycke L.M., Gielen I.M., Simoens P.J., van Bree H.
(2005). Computed tomography and cross-sectional anatomy of the thorax in clinically normal dogs. American Journal of Veterinary Research 66, 12-24.

Gielen I., van Bree H. (2003). Computed tomography in small animals - Part 2. Clinical applications. Vlaams Diergeneeskundig Tijdschrift 72, 168-179.

Hedlund C.S. (2007). Mammary neoplasia. Small Animal Surgery. St. Louis: Mosby Elsevier Fossum T.W., 729735.

Henninger W. (2003). Use of computed tomography in the diseased feline thorax. Journal of Small Animal Practice 44, 56-64.

Johnson V. S., Ramsey I.K., Thompson H., Cave T.A., Barr F.J., Rudorf H., Williams A., Sullivan M. (2004). Thoracic high-resolution computed tomography in the diagnosis of metastatic carcinoma. Journal of Small Animal Practice 45, 134-143.

Joly H., D’Anjou M.-A., Alexander K., Beauchamp G. (2009). Comparison of single-sliced computed tomography protocols for detection of pulmonary nodules in dogs. Veterinary Radiology \& Ultrasound 50, 279-284.

LeBlanc A.K., Daniel G.B. (2007). Advanced imaging for veterinary cancer patients. In: Veterinary Clinics of North America - Small Animal Practice 37, 1059-1077.

LeCouteur R.A. (1999). Current concepts in the diagnosis and treatment of brain tumours in dogs and cats. Journal of Small Animal Practice 40, 411-416.

Lord P., Gomez J. (1985) Lung lobe collapse: pathofysiology and radiologic significance. Veterinary Radiology 26, 187-195.

Mantis P., Baines E. (2007). Computed tomography: why use it in small animal practice? Veterinary Journal 173, 254-271.

McCulloch M., Jezierski T., Broffman M., Hubbard A., Turner K., Janecki T. (2006). Diagnostic accuracy of canine scent detection in early- and late-stage lung and breast cancers. Integrative Cancer Therapies 5, 1-10.

Midthun D.E. (2007). Evaluation of ditzels detected at CT screening. Journal of Thoracic Oncology 2, 159-160.

Müller N.L. (1991). Clinical value of high-resolution ct in chronic diffuse lung disease. American Journal of Roentgenology 157, 1163-1170.

Munden R.F., Hess K.R. (2001). "Ditzels" on chest CT: survey of members of the society of thoracic radiology. American Journal of Radiology 176, 1363-1369.

Nemanic S., London C.A., Wisner E.R. (2006). Comparison of thoracic radiographs and single breath-hold helical ct for detection of pulmonary nodules in dogs with metastatic neoplasia. Journal of Veterinary Internal Medicine 20, 508-515.

Ohlerth S., Scharf G. (2007). Computed tomography in small animals - basic principles and state of the art applications. The Veterinary Journal 173, 254-271.

Otoni C.C., Rahal S.C., Vulcano L.C, Ribiero S.M., Hette K., Giordano T., Doiche D.P., Amorim R.L. (2010). Survey radiography and computerized tomography imaging of the thorax in female dogs with mammary tumors. Acta Veterinaria Scandinavica 52, 20.

Rissetto K.C., Lucas P.W., Fan T.M. (2008) An update on diagnosing and treating primary lung tumors. Veterinary Medicine 103, 154-169.

Rivero M.A., Ramirez J.A., Vazquez J.M., Gil F., Ramirez G., Arenciba A. (2005) Normal anatomical imaging of the thorax in three dogs: computed tomography and macroscopic cross sections with vascular injection. Anatomia Histology Embryologia 34, 215-219. 
Schuller S., Fredericksen M., Schröder H., Meyer-Lindenberg A., Hewicker-Trautwein M., Nolte I. (2005). Computertomographische Differenzierung von intrathorakalen Neoplasien und Entzündungen beim Hund. Berliner und Münchener Tierärztliche Wochenschrift 118, 76-84.

Swensen S.J., Viggiano R.W., Midthun D.E., Müller N.L., Sherrick A., Yamashita K., Naidich D.P., Patze E.F., Hartman T.E., Muhm J.R., Weaver A.L. (2000). Lung nodule enhancement at CT: multicenter study. Radiology 214, 73-80.

Vignoli M., Gnudi G., Laganga P., Gazzola M., Rossi F., Terragni R., Di Giancamillo M., Secchiero D.B., Citi S., Cantoni A.M., Corradi A. (2008). CT-guided fine-needle aspiration and tissue-core biopsy of lung lesions in the dog and cat. European Journal of Companion Animal Practice 17, 23-28.
Vignoli M., Buchholz J., Morandi F., Laddaga E., Brunetti B., Rossi F., Terragni R., Sarli G. (2008). Primary pulmonary spindle cell tumour (haemangiopericytoma) in a dog. Journal of Small Animal Practice 49, 540-543.

Waters D.J., Coakley F.V., Cohen M.D., Davis M.M., Karmazyn B., Gonin R., Hanna M.P., Knapp D.W., Heifetz S.A. (1998). The detection of pulmonary metastases by helical CT: A clinicopathologic study in dogs. Journal of Computer Assisted Tomography 22, 235-240.

Watson C.L., Lucroy M.D. (2002). Primary appendicular bone tumors in dogs. Compendium on Continuing Education for the Practicing Veterinarian 24,128-38.

\section{STRANGELJOEN EN DROES}

Een opvallend beeldende oude ziekteterm, lang bewaard gebleven in het Vlaams (in de zin van dialect gesproken in het vroegere graafschap), maar nu wellicht in onbruik, is strangeljoen: droes bij paarden. In het Engels kennen we het nog als strangles. Het woord werd in beide talen afgeleid van het Latijnse strangulare: wurgen, vermoedelijk via de nu in onbruik geraakte Franse term stranguillon. Vergelijk met estrangler dat étrangler werd.

Door sterke abcesvorming in de nekstreek liepen de paarden met strangeljoen soms gevaar te verstikken. De infectie wurgde hen als het ware. Ze konden enkel gered worden door het aanbrengen van een tracheotube, waarna de infectie door gebrek aan hygiënische maatregelen, met de oorzakelijke Streptococcus equi kiemen overtalrijk aanwezig in de etter, zich verder verspreidde ...

Uiteraard kende het woord tal van varianten in verschillende streken, gaande van strammeloen over strangenuil tot straluin. In het Brabants werd het overwegend streng, strengel, stringel.

Het Algemeen Nederlands nam het woord droes uit het Duits over: Druse, dat zelf afgeleid is van Drüse, wat niets anders betekent dan lymfeklier. Het zijn inderdaad vooral de lymfeklieren in de keelstreek die aangetast worden.

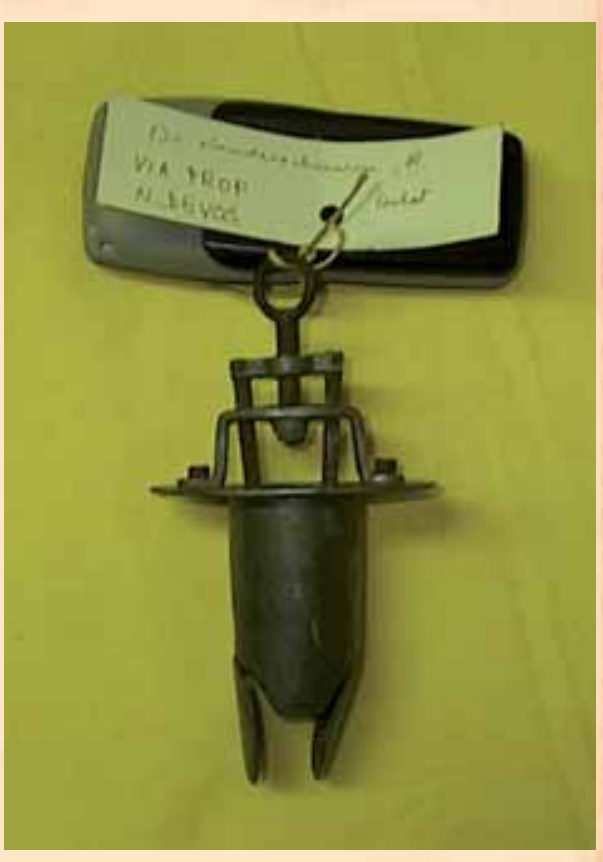

Tracheotube met open vijsbare klepjes uit de museumcollectie diergeneeskundig verleden Merelbeke.

\section{REFERENTIES}

Debrabandere, F. (2005). Oost-Vlaams en Zeeuws-Vlaams Etymologisch Woordenboek, Veen, Amsterdam, p. 387.

Debrabandere, F. (2010). Brabants etymologisch Woordenboek, Waanders, Zwolle \& Davidsfonds, Leuven, p. 533.

De Tier, V. (2003) Woordenboek van de Vlaamse Dialecten. Landbouwwoordenschat. Afl. 10. Het paard, Ugent, p. 282-283. 